\title{
Detection of Storm-Damaged Forested Areas Using Airborne CARABAS-II VHF SAR Image Data
}

\author{
Johan E. S. Fransson, Member, IEEE, Fredrik Walter, Kristina Blennow, Anders Gustavsson, and \\ Lars M. H. Ulander, Member, IEEE
}

\begin{abstract}
Strong winds cause severe damage worldwide to forested land every year. The devastating storms that struck large parts of Europe in late 1999 destroyed the equivalent of several years of normal forest harvesting, amounting to very large economical sums. Therefore, rapid mapping of damaged areas is of major importance for assessment of short-term actions as well as for long-term reforestation purposes. In this paper, the use of airborne CARABAS-II very high frequency (VHF) (20-90 MHz) synthetic aperture radar (SAR) imagery for high spatial resolution mapping of wind-thrown forests has been investigated and evaluated. The investigation was performed at a test site located in southern Sweden and dominated by Norway spruce forests. A regression model estimating radar backscattering amplitude prior to the storm was developed. The estimated amplitudes were compared to measured amplitudes after the storm. The results clearly show that the backscattering amplitude, at a given stem volume, is considerably higher for wind-thrown forests than for unaffected forests. Furthermore, the backscattering from fully harvested storm-damaged areas was, as expected, significantly lower than from unaffected stands. These findings imply that VHF SAR imagery has potential for mapping wind-thrown forests. However, to prevent ambiguities in increased backscattering caused by normal stem volume growth or wind-fellings, multitemporal change detection techniques using VHF SAR images acquired prior to and after wind-fellings would be preferable.
\end{abstract}

Index Terms-CARABAS, SAR, storm damage assessment, VHF.

\section{INTRODUCTION}

$\mathbf{T}$ HE NEED for rapid temporal change detection was manifested in December 1999 in large parts of Europe, where several million cubic meters of trees were wind-thrown. In southern Sweden alone, approximately 4.5 million cubic meters of timber was damaged [1]. Apparently, strong winds are hazardous and cause large economical losses to timber-producing forestry. A perceived high risk of wind-throw in combination

Manuscript received September 29, 2001; revised August 11,2002. This work was supported by the Swedish Research Council for Environment, Agricultural Sciences and Spatial Planning (Formas), the MISTRA-funded research programme SUFOR, Swedish University of Agricultural Sciences (SLU), Swedish National Space Board, Södra Skogsägarna, Sydved AB, and Skogssällskapet.

J. E. S. Fransson is with the Department of Forest Resource Management and Geomatics, Swedish University of Agricultural Sciences, SE-901 83 Umeå, Sweden (e-mail: Johan.Fransson@resgeom.slu.se).

F. Walter is with Dianthus, SE-961 32 Boden, Sweden.

K. Blennow is with the Southern Swedish Forest Research Centre, Swedish University of Agricultural Sciences, SE-230 53 Alnarp, Sweden.

A. Gustavsson and L. M. H. Ulander are with the Department of Surveillance Radar, Swedish Defence Research Agency (FOI), SE-581 11 Linköping, Sweden.

Digital Object Identifier 10.1109/TGRS.2002.804913 with ignorance in relation to whether risk-reducing measures are taken creates a need of decision support among forest managers [2], [3]. In order not to aggravate the economical consequences of a wind-throw occasion, the timber has to reach the pulp industry rapidly, as damaged logs often get infected by fungi, making them less suitable for pulp production. Today, mapping of wind-thrown forests is mostly performed by manual ground-based inventory and by airborne ocular inspection. These methods are expensive and time-consuming. Procedures for rapid mapping of wind-thrown forests are thus needed to meet requirements from the forest industry in order to guide harvesting resources to individual storm-damaged forested areas. Furthermore, the mapping is needed for the planning of actions in relation to reforestation.

The unique CARABAS-II radar system is developed by the Swedish Defence Research Agency (FOI) [4]. It operates at horizontal-horizontal (HH)-polarization in the lower very high frequency (VHF)-band (20-90 MHz, corresponding to wavelengths between 3.3 and $15 \mathrm{~m}$ ) with a ground resolution of approximately $2.5 \mathrm{~m}$. By providing its own illumination source, a radar sensor is capable of operating independently of daylight and weather conditions. This is a great advantage compared to using optical data, especially for the application of mapping wind-thrown forests, as storms in northern Europe often occur late in autumn or during the winter period when daylight is limited. Furthermore, the CARABAS system is different from ordinary microwave synthetic aperture radar (SAR) sensors. As a rule of thumb, only objects with a spatial extent of at least half the wavelength contribute significantly to the backscattering. This makes smaller objects such as grass, shrubs, leaves, twigs, and smaller branches "invisible" to the CARABAS sensor, while backscattering from these kinds of objects are detectable for microwave SAR sensors. When imaging a forest, the electromagnetic waves transmitted from CARABAS penetrate the forest canopy. Hence, the major backscattering will come from large elements, i.e., tree trunks and primary branches. This is in contrast to microwave SAR sensors, for which most of the backscattering takes place in the top layers of the canopy [5].

Previous results, based on physical modeling and empirical analyses, have shown a linear relationship and a high correlation between the radar backscattering and coniferous forest stem volume at the VHF-band [6]-[10]. This is explained by the dihedral reflection between the ground and the tree trunks being the dominant scattering mechanism [7]. Furthermore, no saturation of the backscattered signal has been observed for stem volumes up to about $1000 \mathrm{~m}^{3} \mathrm{ha}^{-1}$ [10]. 


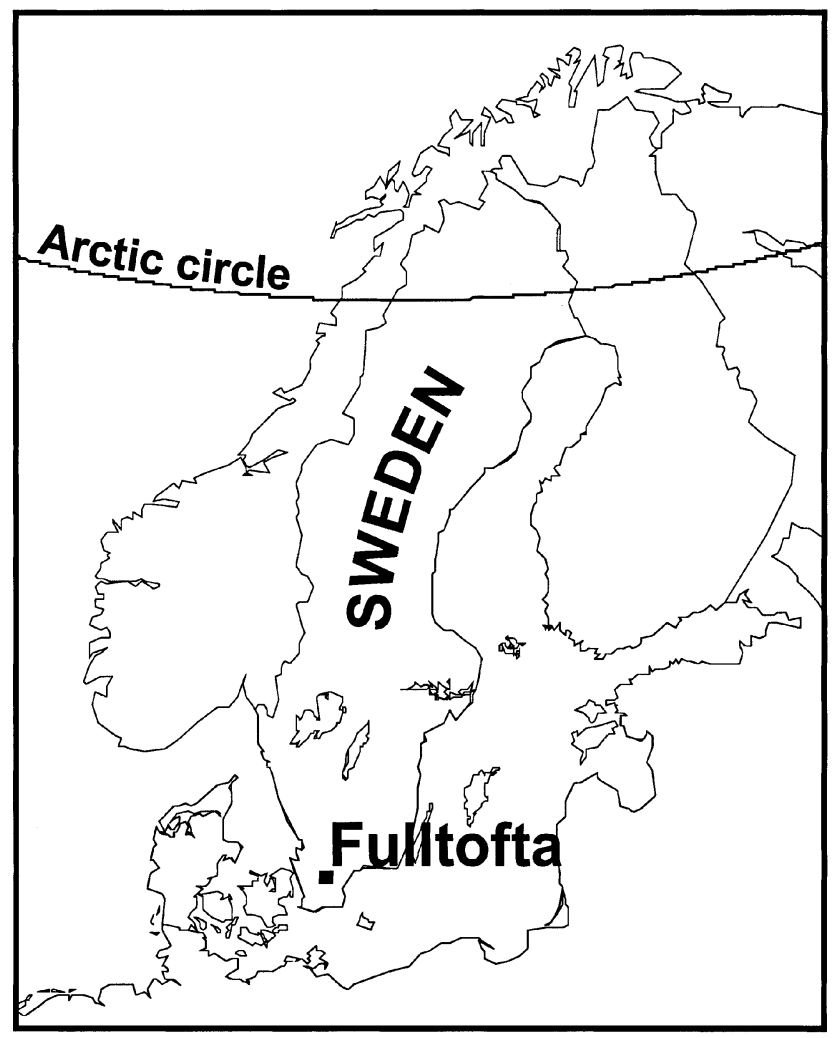

Fig. 1. Location of the Fulltofta test site.

It should be noted that the above results are valid for HH-polarization. At this polarization, the attenuation from the tree trunks is very small, as the electric field is perpendicular to the trunks. Calculations performed at vertical-vertical polarization show less correlation between backscattering and stem volume.

In wind-thrown forests, an increase in radar backscattering is expected for HH-polarization, since the electric field becomes more parallel to the trunks. Moreover, in dense forests the windthrown trees often cross each other, building up thick layers of trunks (often 2-4 $\mathrm{m}$ in height). This implies that the ground reflection does not significantly reduce the backscattering, as would be the case when the trunks lie on the ground.

In a previous pilot study performed at a nearby test site, the use of CARABAS-II VHF SAR imagery for high spatial resolution mapping of wind-thrown forests has been studied [11]. In the pilot study, a regression model estimating forest stem volume from radar backscattering amplitude was used to retrieve stem volume for storm-damaged areas. The estimated volumes were then compared with subjectively inventoried stem volumes. The results indicated that the backscattering amplitude is considerably higher for wind-thrown forests in comparison with backscattering from unaffected forests.

In this paper, the use of airborne CARABAS-II VHF SAR imagery for rapid high spatial resolution mapping of wind-thrown forests has been further investigated and evaluated.

\section{GRound AND Aerial Photography DatA}

The forested area Fulltofta, located in southern Sweden (Latitude $55^{\circ} 53^{\prime}$, Longitude $13^{\circ} 39^{\prime}$ ) was selected as the test site for this study (Fig. 1). The test site covers an area of

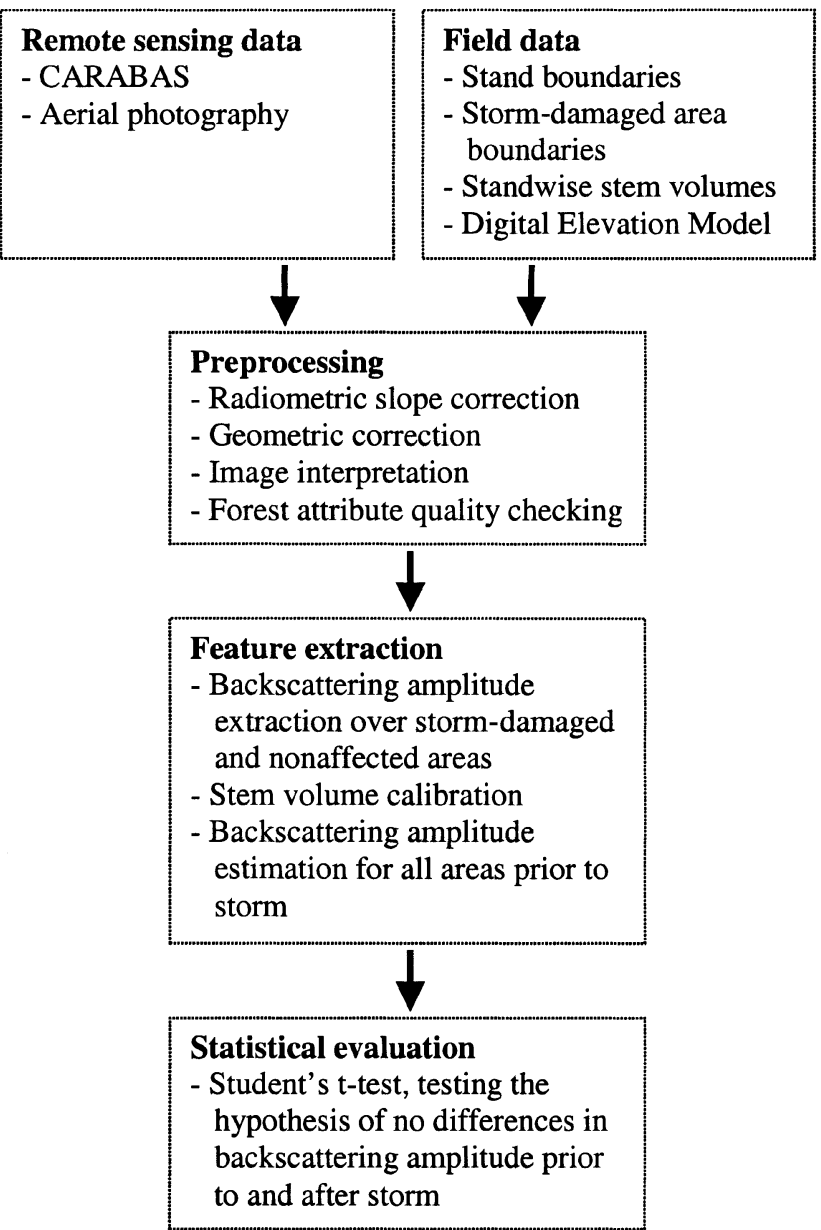

Fig. 2. Flowchart illustrating the methodology applied in this study.

about $10 \times 10 \mathrm{~km}^{2}$ and is dominated by Norway spruce (Picea abies) and beech (Fagus sylvatica) forests. On December 3, 1999, strong winds caused extensive damage to a large number of spruce stands. The soils in the area are mainly till, i.e., coarse and predominantly podsolic soils of glacial origin, but glaciofluvial and organogenic types are also present. Inside the spruce forests, field and bottom layer vegetation are sparse or absent. The ground elevation varies from $60-160 \mathrm{~m}$ above sea level, with moderate relief.

As an overview of the study, a flowchart illustrating the complete processing procedure is shown in Fig. 2.

Forest stem volumes prior to the storm were collected from the existing subjectively inventoried forest database. The stem volume recordings originated from 1995 and were, therefore, adjusted to the growing season prior to the storm. After the storm, two different techniques were used for mapping of wind-thrown forested areas. The first technique was ground-based using a global positioning system (GPS) technique for delineating storm-damaged areas. The accuracy for the GPS measurements was in the order of $\pm 5 \mathrm{~m}$. The second technique consisted of interpretation of color aerial photographs. The photographs used were acquired over the test site on December 21, 1999, resulting in digital images with a spatial resolution of $0.7 \times 0.7 \mathrm{~m}^{2}$. These were used for manual delineation of storm-felled areas. For each area, the fraction of damaged trees was also visually 
interpreted. Finally, the delineated areas were rectified and transferred to the orthogonal coordinate system used.

The two complementary datasets were merged, forming a complete set of storm-felled areas within the test site. In total, the dataset consisted of 83 storm-felled areas of sizes ranging from 0.1-3.2 ha.

An additional aerial photography campaign was conducted on March 15, 2000, about two weeks after CARABAS-II image acquisition. The photography was delayed by two weeks due to cloudy weather conditions. The registered black-and-white aerial photographs were digitized to a spatial resolution of $0.5 \times 0.5 \mathrm{~m}^{2}$ and rectified to the orthogonal coordinate system used. These images were used for determining the condition of the storm-felled areas regarding whether the storm-felled trees were harvested or not at the time of CARABAS-II image acquisition. This procedure reduced the initial dataset to 16 storm-felled areas (0.1-1.9 ha) and formed a new dataset of 22 fully harvested areas.

From the forest database, 34 reference stands were chosen to represent nondamaged spruce forested areas, with stem volumes in the range of $170-540 \mathrm{~m}^{3} \mathrm{ha}^{-1}$. The backscattering amplitude from these stands was used as a reference and for calibration of the subjectively inventoried stem volumes.

In order to effectively extract image data from the different areas of interest, the delineations were stored as vector coverages in a geographic information system and transformed to raster representation. The raster regions were shrunk by $5 \mathrm{~m}$ in order to get rid of geometrical errors in the datasets used.

\section{SAR DATA}

CARABAS-II VHF SAR image data were acquired over the Fulltofta test site on February 25, 2000. The subsequent SAR processing resulted in three complex slant range images. The images were captured at an altitude of $4400 \mathrm{~m}$ and from three different flight directions separated by $90^{\circ}$. The incidence angles were in the range of $45^{\circ}$ to $70^{\circ}$. The image dataset was geometrically corrected to the local orthogonal map projection using a digital elevation model (DEM) and recorded flight parameters [12]. In order to perform radiometric calibration of the SAR images [13], a trihedral outside the test site was imaged during the day of flight using the same imaging geometry as over the test site. The radar cross section in square meters is determined from the calibrated SAR image by squaring the magnitude of the complex pixel value.

Disturbing nonforest objects, e.g., power lines, buildings, and fences, were manually detected and excluded from the image data. Areas affected by image artifacts, i.e., produced by strong scattering elements originating from the opposite illumination side of the aircraft, were also manually excluded from the images.

The backscattering amplitude $s^{\circ}$ for each forest area was calculated from SAR image data according to

$$
s^{\circ}=\frac{1}{n} \sum_{k=1}^{n} \sqrt{\left(\operatorname{Re}_{k}^{2}+\operatorname{Im}_{k}^{2}\right) \frac{\cos \psi_{k}}{d x d r}-\sigma_{\text {noise }}^{\circ}}
$$

where $n$ is the number of pixels for a given area; $\operatorname{Re}_{k}$ and $\operatorname{Im}_{k}$ are the real and imaginary part of the complex $k$ th pixel value; $\cos \psi_{k}$ is the projection factor for slope correction [14] calculated using a DEM; $d x$ and $d r$ are the pixel sizes in azimuth and slant range direction; and $\sigma_{\text {noise }}^{\circ}$ is the noise constant calculated as

$$
\sigma_{\text {noise }}^{\circ}=\frac{1}{m} \sum_{k=1}^{m}\left(\operatorname{Re}_{k}^{2}+\operatorname{Im}_{k}^{2}\right) \frac{\cos \psi_{k}}{d x d r}
$$

where $m$ is the number of pixels over a smooth lake surface within the test site, assumed to have an average signal near the system noise floor. Further details about (1) and (2) are described in [6].

\section{METHODS}

In order to estimate backscattering amplitude for the stormaffected areas prior to the storm and to calibrate the biased subjectively inventoried stem volumes at the Fulltofta test site, linear regression models, developed in a previous study [6], were applied. The objectively inventoried stem volume was related to amplitude according to

$$
v_{i}=\alpha_{0}+\alpha_{1} s_{i}^{\circ}+\varepsilon_{i}+\delta_{i} .
$$

Correspondingly, the amplitude was related to stem volume as

$$
s_{i}^{\circ}=\beta_{0}+\beta_{1} v_{i}+\varepsilon_{i} .
$$

The regression coefficients $\alpha_{0}, \alpha_{1}, \beta_{0}$, and $\beta_{1}$ were estimated by means of ordinary least squares (OLS). Further details about (3) and (4) are described in [6].

The regression model used for calibration of the subjectively inventoried stem volumes at the Fulltofta test site was developed according to

$$
v_{\text {calibrated }}=\alpha_{2}+\alpha_{3} v_{\text {subj }}+\varepsilon_{i}
$$

where $v_{\text {subj }}$ is the subjective stem volume for each stormaffected area, and $\varepsilon_{i}$ is the random deviation from the true stem volume for forest area $i$. The variable $\varepsilon_{i}$ is assumed to be independent and normally distributed with zero expectation and variance $\operatorname{Var}(\varepsilon)$ for each $i$. The model was based on the reference stands using stem volume estimated from (3) as the dependent variable and the subjectively inventoried stem volume as the independent variable. The regression coefficients $\alpha_{2}$ and $\alpha_{3}$ were estimated by means of OLS.

The backscattering amplitude from the storm-damaged areas varied considerably among the images acquired from the three different flight directions. In agreement with other linear objects, e.g., power lines and fences, the elongated trunks will give a higher response if they are parallel to the flight direction. Therefore, the measured amplitude was chosen as the maximum value from the available flight paths.

Finally, estimated backscattering amplitudes prior to the storm, using calibrated stem volumes in model (4), were compared to measured amplitudes after the storm. The Student's t-test was performed to test the null hypothesis $H_{0}$ of no difference between the backscattering amplitudes prior to and after the storm for the storm-felled areas, fully harvested areas, and reference stands, respectively. 


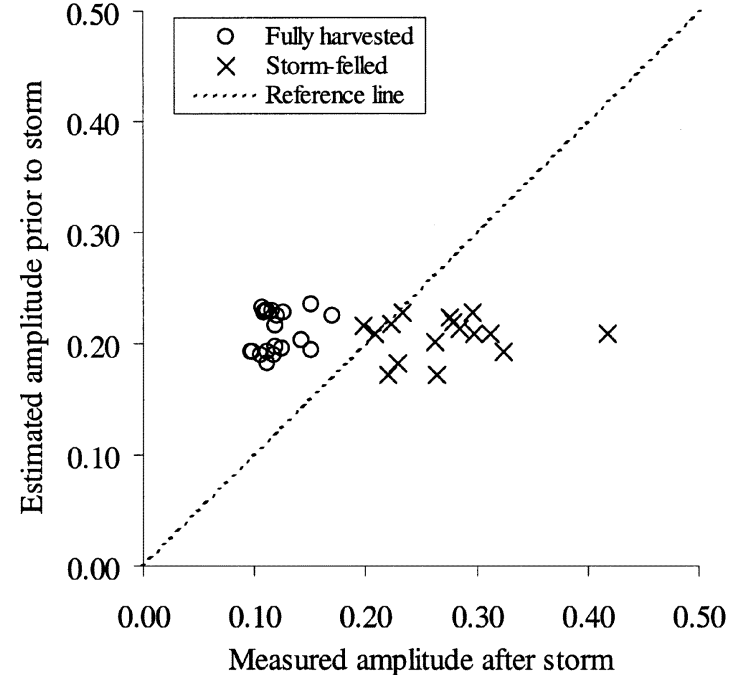

Fig. 3. Backscattering amplitude prior to (estimated) and after (measured) storm for storm-felled and fully harvested areas, respectively. In the storm-damaged areas, the fraction of storm-felled trees varied between $40 \%$ and $100 \%$. The dashed line corresponds to unchanged forest conditions.

TABLE I

Statistics From the Student's T-Test, Testing the Hypothesis of NO DifFERENCES IN AMPLITUDE PRIOR TO AND AFTER THE STORM

\begin{tabular}{lllll}
\hline Forest area type & $\begin{array}{l}\text { Number of } \\
\text { observations }\end{array}$ & $\begin{array}{l}\text { Mean } \\
\text { difference }\end{array}$ & $\begin{array}{l}\text { Standard } \\
\text { deviation }\end{array}$ & $p$-value \\
\hline Storm-felled areas & 16 & 0.0622 & 0.0561 & 0.0001 \\
Fully harvested areas & 22 & -0.0906 & 0.0229 & 0.0001 \\
Reference stands & 34 & 0.0071 & 0.0306 & 0.1870 \\
\hline
\end{tabular}

\section{RESULTS}

The regression coefficients $\alpha_{2}$ and $\alpha_{3}$ for the developed stem volume calibration model (5) were estimated to 301 and 0.60 , respectively. Hence, the calibration function increased the lower subjective stem volumes, leaving the highest volumes, in principle, unchanged. Any systematic differences in SAR image calibration between the Fulltofta test site and the test site in [6] were also compensated for, after applying calibration function (5). The measured amplitudes at the Fulltofta test site can, therefore, be accurately compared to the estimated amplitudes prior to the storm.

The results from comparing estimated backscattering amplitudes prior to the storm with measured amplitudes after the storm are shown in Fig. 3.

The Student's t-test showed significant differences in amplitude prior to and after the storm for both storm-affected and fully harvested areas, respectively. The amplitude for the storm-felled areas after the storm was significantly higher than prior to the storm. The null hypothesis $H_{0}$ could be rejected at the $0.1 \%$ significance level. For the case of fully harvested areas, the amplitude after the storm was, as expected, significantly lower than prior to the storm. Here, $H_{0}$ could also be rejected at the $0.1 \%$ significance level (Table I).

A photograph taken from one of the storm-felled areas is shown in Fig. 4. In Figs. 5 and 6, a visual comparison can be

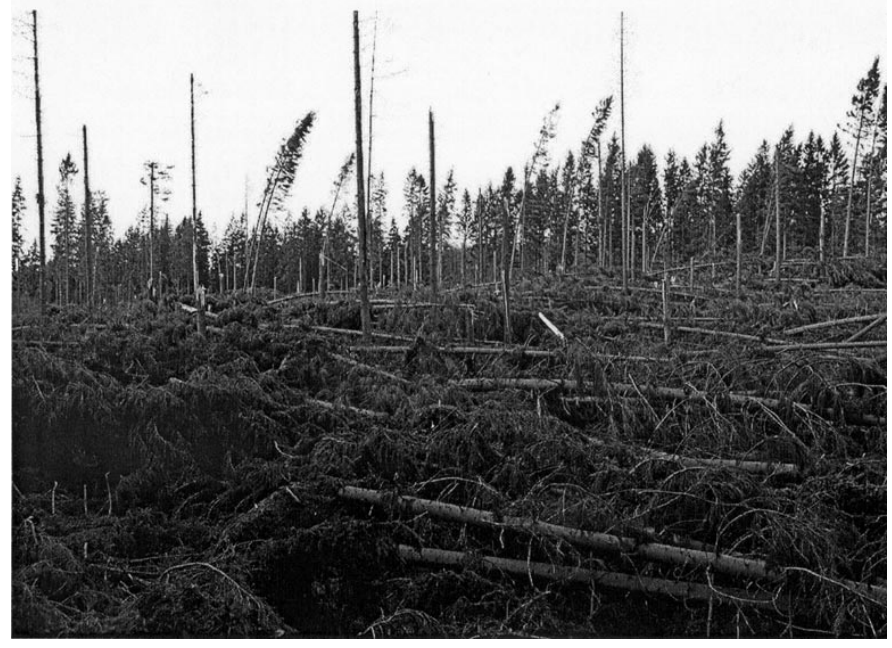

Fig. 4. Photograph taken from one of the storm-felled areas.

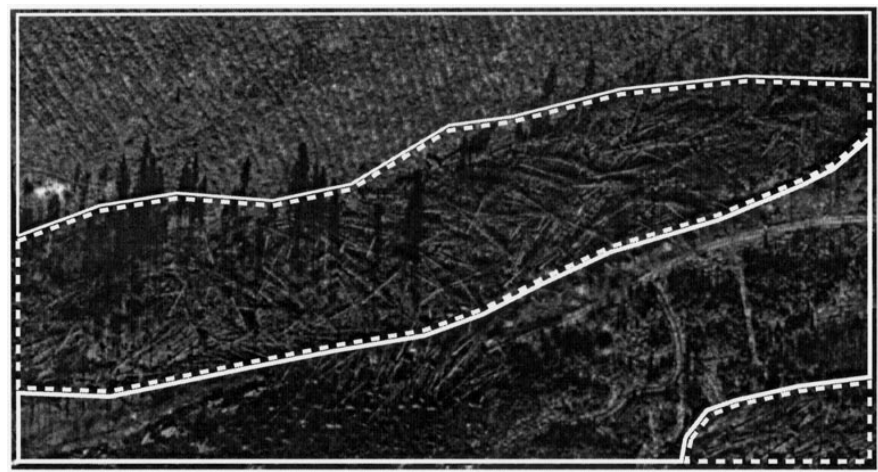

Fig. 5. Aerial photograph of a storm-damaged area, corresponding to the CARABAS-II images in Fig. 6. The areas delineated with dashed and solid lines correspond to storm-felled and fully harvested areas, respectively.

made between an aerial photograph and two CARABAS-II images acquired perpendicular to each other over a wind-thrown forested area at the test site. The area is partially covered with trees laying on the ground and partially fully harvested. In areas with trees laying on the ground parallel to the flight direction, the backscattering amplitude is noticeably higher than the surrounding area [see Fig. 6(a)]. The storm-felled trees also show a distinct elongated pattern in the CARABAS-II image. In contrast, as seen in Fig. 6(b), the backscattering amplitude is lower while imaging the forest perpendicular to the main direction of the storm-felled trees. In areas where the timber has been fully harvested, the backscattering amplitude is even lower.

\section{DISCUSSION AND CONCLUSION}

In this study, the potential for high spatial resolution mapping of wind-thrown forests using CARABAS-II VHF SAR imagery has been investigated and evaluated. A storm-damaged forested area in southern Sweden dominated by Norway spruce was chosen as the test site. Visually interpreted aerial photographs, acquired prior to and after the CARABAS-II flight, together with subjectively inventoried stem volumes, served as ground truth data for the analysis. A nearby test site was used for establishing the relation between backscattering amplitude and 


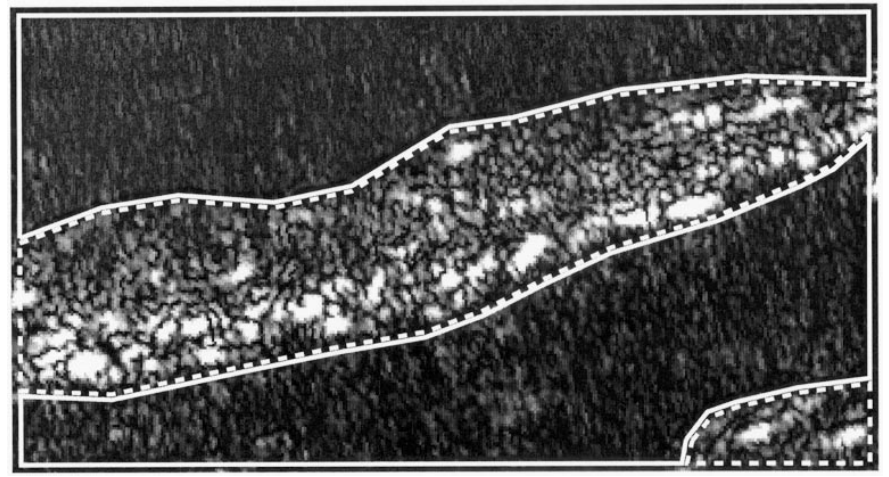

(a)

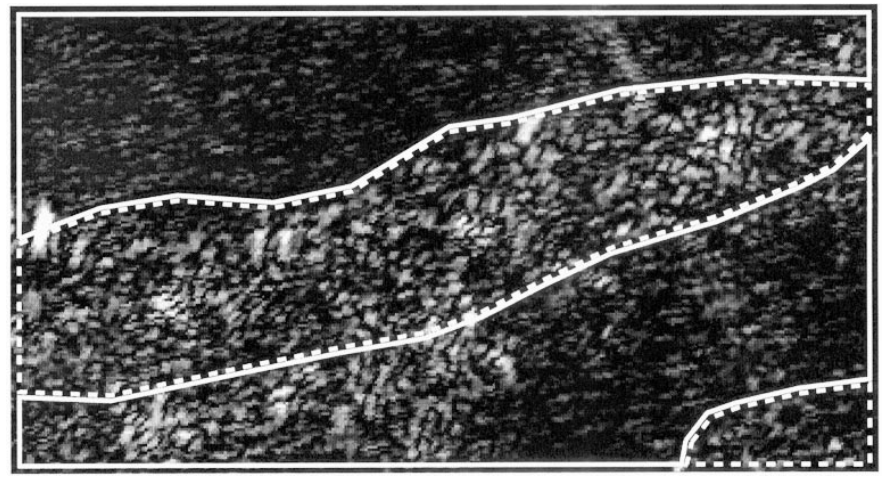

(b)

Fig. 6. CARABAS-II images acquired from two perpendicular flight directions of a storm-damaged area, (a) along the image and (b) across the image, corresponding to the aerial photograph in Fig. 5. The areas delineated with dashed and solid lines correspond to storm-felled and fully harvested areas, respectively. In (a), notice the difference in backscattering amplitude between the two parts, evident as differences in gray level, and the elongated patterns from the trunks of the storm-felled trees. In (b), the contrast between storm-felled and fully harvested areas is clearly reduced due to the flight direction being perpendicular to the laying trunks.

spruce stem volume, as no objectively inventoried stem volumes were available at the storm-damaged test site at the time of the storm. The results clearly show that the backscattering amplitude for storm-felled areas is significantly higher than for nondamaged areas at a given stem volume. As expected, the amplitudes for the fully harvested areas were significantly lower than the estimated amplitudes prior to storm.

The major backscattering mechanism in VHF SAR for normal coniferous forest conditions is the dihedral reflection, i.e., trunk-ground interaction [7]. The initial expectation in the previous pilot study described in [11] was that the backscattering amplitude for wind-thrown forests should be lower than for nonaffected stands. Instead, the results in [11] indicated an increase in backscattering amplitude, i.e., an increase in estimated stem volume after the storm. These results have been confirmed and validated through the empirical observations in the present study. The expected decrease in backscattering amplitude due to loss in dihedral reflection caused by the horizontally oriented tree trunks was more than fully compensated. This compensation is likely due to an increase in radar backscattering for $\mathrm{HH}$-polarization, since the electric field becomes more parallel to the trunks. To investigate and completely understand the different mechanisms involved, physical modeling of scattering from storm-felled forests must be carried out.

A visible pattern of elongated trunks clearly appears in the CARABAS-II images [Fig. 6(a)]. In addition to the high amplitude, this pattern could likely be used as an additional discriminating factor between storm-damaged and nonaffected areas. However, the patterns are not always visible, depending on the flight direction and the direction of the trunks [Fig. 6(b)]. Although local variation in wind direction may occur, the additional information could be provided by arranging the flight direction in correspondence with the prevailing wind direction during the storm. For some of the storm-felled areas, the measured backscattering amplitude differs little from that expected for unaffected stands, i.e., they are found close to the reference line in Fig. 3. This might be explained by a nonoptimal flight direction, by a small fraction of storm-felled trees within the damaged area, or by a discrepancy between the updated stem volumes in the forest stand database and the true conditions in the stand at the time of the storm. In an operational scenario, the kind of analysis presented here could be used for guiding field personnel to areas likely to have been damaged by the storm. A small part of erroneously included or excluded storm-felled areas would, therefore, have to be accepted. By using multitemporal CARABAS-II image data, collected prior to and after the storm, the mentioned ambiguities could be reduced. In conclusion, the results imply that CARABAS-II VHF SAR has potential for rapid high spatial resolution mapping of wind-thrown forests.

\section{ACKNOWLEDGMENT}

The authors would like to thank B. Edlund and J. Norgren at Skogssällskapet for providing forest and GPS data. The authors acknowledge K. Djurvall (Southern Swedish Forest Research Centre, SLU, Alnarp) for aerial photo interpretation, R. Övergaard (Southern Swedish Forest Research Centre, SLU, Alnarp), the Swedish National Board of Forestry, and Sydved $\mathrm{AB}$ are acknowledged for assistance in the field survey, and H. Reese (SLU, Umeå) for revision of the language. The aerial photography was performed by Scankort A/S, Denmark and L\&L Flygbildteknik AB, Sweden. Finally, the authors would like to thank the reviewers for their comments.

\section{REFERENCES}

[1] Swedish National Board of Forestry, Distributed Fax Message (in Swedish), Dec. 8, 1999.

[2] K. Blennow and O. Sallnäs, "Modelling the risk of windthrow for better forestry decisions," in Risk Analysis II, C. A. Brebbia, Ed. Ashurst, U.K.: Wessex Inst. Technology, 2000, pp. 73-82.

[3] - "Risk perception among non-industrial private forest owners," Scan. J. Forest Res., vol. 17, pp. 472-479, 2002.

[4] H. Hellsten, L. M. H. Ulander, A. Gustavsson, and B. Larsson, "Development of VHF CARABAS II SAR," in Proc. Radar Sensor Technology, vol. SPIE 2747, Orlando, FL, Apr. 8-9, 1996, pp. 48-60.

[5] J.E. S. Fransson and H. Israelsson, "Estimation of stem volume in boreal forests using ERS-1 C- and JERS-1 L-band SAR data," Int. J. Remote Sens., vol. 20, pp. 123-137, 1999.

[6] J. E. S. Fransson, F. Walter, and L. M. H. Ulander, "Estimation of forest parameters using CARABAS-II VHF SAR data," IEEE Trans. Geosci. Remote Sensing, vol. 38, pp. 720-727, Mar. 2000.

[7] G. Smith and L. M. H. Ulander, "A model relating VHF-band backscatter to stem volume of coniferous boreal forest," IEEE Trans. Geosci. Remote Sensing, vol. 38, pp. 728-740, Mar. 2000. 
[8] J. E. S. Fransson, A. Gustavsson, L. M. H. Ulander, and F. Walter, "Mapping of forest stand parameters using VHF SAR data," in Proc. EUSAR 2000 Conf., 3rd European Conf. Synthetic Aperture Radar, Munich, Germany, May 23-25, 2000, pp. 157-160.

[9] _ - "Towards an operational use of VHF SAR data for forest mapping and forest management," in Proc. IGARSS, Honolulu, HI, July 24-28, 2000, pp. 399-401

[10] L. M. H. Ulander, J. Askne, J. E. S. Fransson, A. Gustavsson, T. Le Toan, T. Manninen, J.-M. Martinez, P. Melon, G. Smith, and F. Walter, "Retrieval of stem volume in coniferous forest from low VHF-band SAR," in Proc. IGARSS, Honolulu, HI, July 24-28, 2000, pp. 441-443.

[11] J. E. S. Fransson, A. Gustavsson, L. M. H. Ulander, and F. Walter, "Mapping of wind-thrown forests using CARABAS-II VHF SAR image data," in Proc. IGARSS, Sydney, Australia, July 9-13, 2001, pp. $2737-2739$

[12] F. Walter, J. E. S. Fransson, and P.-O. Frölind, "Fully automatic geocoding of CARABAS-II VHF SAR images," in Proc. IGARSS, Hamburg, Germany, June 28-July 2, 1999, pp. 569-573.

[13] L. M. H. Ulander, P.-O. Frölind, and T. Martin, "Processing and calibration of ultra-wideband SAR data from CARABAS-II," in Proc. CEOS SAR Workshop, vol. ESA SP-450, Toulouse, France, Oct. 26-29, 1999, pp. 273-278.

[14] L. M. H. Ulander, "Radiometric slope correction of synthetic-aperture radar images," IEEE Trans. Geosci. Remote Sensing, vol. 34, pp. 1115-1122, Sept. 1996.

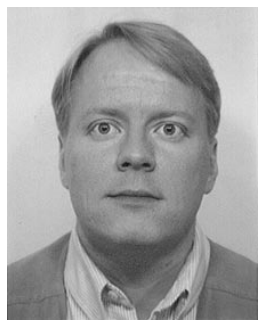

Johan E. S. Fransson (M'02) was born in Karlshamn, Sweden, in 1967. He received the M.S and $\mathrm{Ph} . \mathrm{D}$. degrees in forestry from the Swedish University of Agricultural Sciences (SLU), Umeå, Sweden, in 1992 and 1999, respectively.

Since 1993, he has been with the Department of Forest Resource Management and Geomatics, SLU, Umeå. In 2000, he was employed as an Assistant Professor in forestry remote sensing. His main research interest concerns analysis of SAR images for forestry applications.

Dr. Fransson received the International Space University Certificate from the Royal Institute of Technology in Stockholm, Sweden, in 1995 and the award from "Kungliga Skytteanska samfundet" to a young researcher at SLU, Umeå, in 2002 .

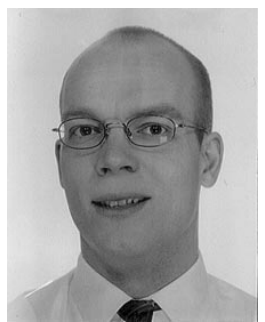

Fredrik Walter was born in Sundsvall, Sweden, in 1967. He received the M.S. and Ph.D. degrees in forestry from the Swedish University of Agricultural Sciences (SLU), Umeå and Uppsala, Sweden, in 1994 and 1999, respectively.

Between 1994 and 2000, he was with the Centre for Image Analysis, SLU, Uppsala, Sweden Currently, he is with Dianthus, Boden, Sweden, developing software applications in the field of geographic information technology.

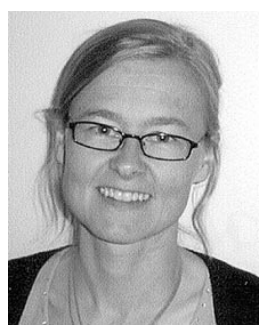

Kristina Blennow received B.S. degree, Teacher's Diploma, and Ph.D. degree from Lund University, Lund, Sweden, in 1983, 1985, and 1997, respectively.

Since 1998, she has been an Assistant Professor at the Southern Swedish Forest Research Centre, Swedish University of Agricultural Sciences (SLU), Alnarp, Sweden. Her current research interest is in risk management, in particular in relation to climate-related hazards and climate change. This work includes studies on risk perception as well as the development of computer models and mapping techniques for characterizing forestry hazards, such as damage by wind and frost at a landscape level. The computer models are used to provide decision support to decision makers. She is, furthermore, interested in philosophical aspects of risk, the precautionary principle, and sustainability, and she explores how active risk management can contribute to the sustainable multiple use of the forest resource.

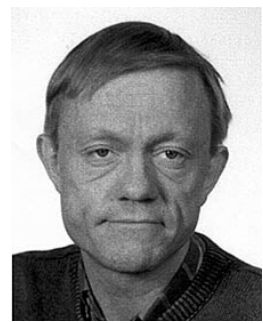

Anders Gustavsson received the M.S. degree in applied physics and electrical engineering from Linköping University, Linköping, Sweden, in 1982.

He joined the Swedish Defence Research Agency (FOI), Linköping, Sweden, in 1982 to work with the development of a computer-based SAR processor for microwave systems. He has been with the CARABAS project since 1990, where his current work is in signal processing techniques for low-frequency synthetic aperture radar. He has also participated in a number of field campaigns focusing on forestry and foliage penetration problems.

Mr Gustavsson was presented with an IEEE Prize Paper Award for a manuscript on the CARABAS sensor in 1993.

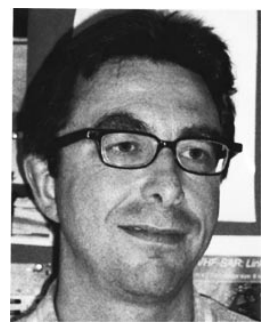

Lars M. H. Ulander (S'86-M'90) received the M.S. degree in engineering physics, in 1985, and the Ph.D. degree in electrical and computer engineering, in 1991, both from Chalmers University of Technology (CTH), Göteborg, Sweden.

Currently, he is leading a research group at the Swedish Defence Research Agency (FOI), Linköping, Sweden, focusing on advanced signal processing techniques using low-frequency (UHFand VHF-band) synthetic aperture radar (SAR) systems, as well as implementing such techniques in airborne experimental and technology demonstrators. He was Assistant Professor at CTH between 1992 and 1995. Since 1995, he has worked at FOI, where he was appointed Director of Research in 2001. Since 1999, he has acted as Adjunct Professor in radar remote sensing at CTH. His research area includes radar and electromagnetics, in particular signal processing, SAR, and electromagnetic scattering. He has worked on a number of radar research problems including SAR processing, interferometry, calibration, validation, and electromagnetic modeling, as well as organized numerous field campaigns. $\mathrm{He}$ is the author or coauthor of about 150 professional publications, of which more than 30 are in refereed journals. He is the holder of four patents and is listed in Who's Who in Electromagnetics.

Dr. Ulander is a member of the Remote Sensing Committee at the Swedish National Space Board. 